\title{
OBSERVATIONAL NETWORK DESIGN FOR CLIMATE
}

\author{
Carl Wunsch \\ Massachusetts Institute of Technology, Rm. 54-1524, Cambridge MA 02139 USA, Email: cwunsch@mit.edu
}

\section{INTRODUCTION}

"Prediction is difficult, particularly when it's about the future." Danish folk-saying.

This paper differs from most of the other plenary discussions in that no one is to blame for it, except me. Although I have read the relevant white papers dealing with this subject, and have tried to synthesize their conclusions, so many difficult issues are involved in observational network design, that producing a true consensus proved difficult. In practice, it is difficult to perceive the scientific/technical future of observing systems much beyond 10 or 20 years, particularly as technology and science deliver unexpected capabilities or unforeseen events impose their own agenda. (Wars are the most obvious cause, but so are financial and Arctic ice meltdowns, etc.). Whatever the goals, it must be appreciated at the outset that climate observing systems must be designed to operate, and thus evolve, indefinitely - as the time scales embedded in the system extend far beyond any existing instrumental records.

The fundamental and most difficult issues in discussion of observations of any kind are all related to the two questions: (1) What is one trying to observe? (2) How well does it have to be done? A consequent, but less fundamental, third question is: (3) What is the current capability and in what ways does it remain inadequate? Few of the speakers or papers prepared for the Conference addressed these questions even tangentially. If the first two questions can be answered, everything else is technical detail---perhaps expensive to determine---but in principle always possible by known methods.

Many good reasons exist for observing the ocean, and they have competing and conflicting requirements. An observational system designed to understand climate change necessarily differs radically from ones intended for mesoscale eddy forecasting or for understanding the basin-scale surface exchanges of carbon dioxide. Systems attempting to be all things to all people are likely to be inadequate for any purpose.

In trying to summarize what thinking has emerged, I have chosen to here (1) to focus on climate time scales beyond about 3-5 years, and (2) to infer that the problem is fundamentally a global one. Although the goals are focused on climate, many of the issues arising in meeting them are, however, generic, applying to almost all observational network design, and I will make some comments about them at the end.

\section{THE OCEAN IN CLIMATE}

Understanding of the global ocean has matured greatly over the last 25 years, and thus I make the inference/assumption that all proposals for observing systems and their synthesis must now be quantitative ones.

We have (largely) left behind the exploration era, in which simply documenting the existence of variability or of some pathway or phenomenon represented great progress. Now we have the more difficult problem of describing how well that variability, pathway, or phenomenon is depicted and determining its potential consequences evaluated in major part because societal concerns often dominate. Agreeing to spend millions or billions of euros on observing systems demands a high degree of quantitative evaluation.

\subsection{Assumptions}

(1) The problems of climate are global: understanding of the nature of the mean ocean, and its variability cannot ultimately be isolated from even remote regions. Dependence on distant regions is only weakly a function of the space-time scale of any particular disturbance---in many cases, signals of change are transmitted globally extremely rapidly, but with final equilibrium requiring decades to thousands of years.

(2) Any true global observing system will be an amalgam of disparate elements such as altimeters, drifters, gliders, floats, and moorings.

(3) True understanding of the climate system can be claimed only if all the observations are considered (that is, one cannot arbitrarily suppress various data types either because they are inconsistent with others or inconvenient).

(4) True understanding of the climate system requires a synthesis of the disparate data types with the dynamics believed to govern the system.

(5) The only way known to me to address (3) and (4) above is via formal estimation systems applied to numerical ocean general circulation models.

(6) Quantitative use of data and models cannot be done without adequate knowledge of the likely errors of both.

(7) The problem of prediction (forecasting) is distinct in 
methodology and difficulties from that of state estimation and although related, the two are best discussed separately.

(8) Because, particularly, of the societal interests in climate change, both state estimates and forecasts need to be accompanied by careful discussion of the reliability of the results---and the reliability in turn depends upon the data accuracies and coverage, model skill, and the methodology used to form model-data syntheses. Not all estimates are equally reliable for all purposes.

(9) Any useful ocean observation system must be openended in time---there is no low-frequency cut-off to the time scales over which the system is capable of change, and new physics always enters as the time scale increases. Much of what we see today may well be the result of changes and forces acting in the distant past. Design considerations must thus include the ability to sustain a high quality system indefinitely so that those long times are ultimately observed.

\section{SOME BACKGROUND}

As the white papers (Heimbach et al., 2010; Stammer et al., 2010; Oke et al., 2010) prepared for the Conference show, the feasibility of model/data syntheses has been demonstrated over the past decade. Much room for improvement exists in all aspects of the system, but that the community knows how to carry out such calculations is hardly in doubt. What is in doubt is whether there is sufficient understanding in the observational and theoretical communities of what these solutions mean, what are their (various) limitations, and what future capabilities both could, and need, to exist.

Here I will sketch some aspects of the above assumptions to show the directions in which we need to go.

\subsection{Globality}

For good practical reasons, most oceanography has always been done regionally. But the ocean responds to changes (signals) carried extremely rapidly both through barotropic motions and via the atmosphere, but also extremely slowly, and over arbitrarily long distances. A shift in SST (Sea SurfaceTtemperature) in the tropical Pacific will influence the wind system over the North Atlantic within a few days via the disturbed meteorology. Injection of glacial ice melt is signalled through global ocean mass shifts achieved through barotropic adjustment within days. On the other hand, baroclinic adjustments take place in the ocean over decades and much longer (Cessi et al., 2004; Stammer 2008) and density, temperature, etc., can at any given location and time be responding to shifts that took place in the remote past. Figure 1 from the Heimbach et al.
(2010) white paper shows the sensitivities of $25^{\circ} \mathrm{N}$ enthalpy transports across $25^{\circ} \mathrm{N}$ to deep temperature changes 15 years earlier. Over yet longer time scales, the entire three-dimensional ocean comes into the story.

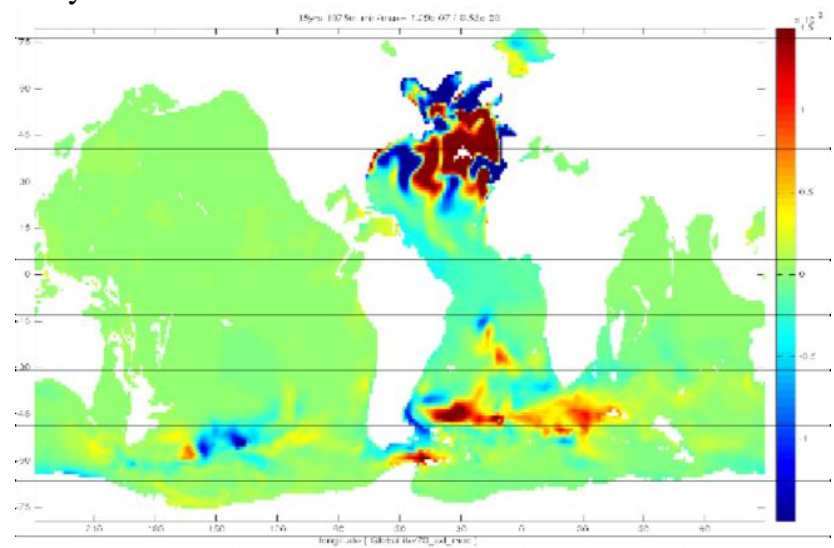

Figure 1 Sensitivities to $25^{\circ} \mathrm{N}$ North Atlantic enthalpy transports to deep (2950 m) temperature shifts 15 years previously.

Consider one example: it has been argued (e.g., Geirsdottir et al., 2008) that the stability of ice sheets in both Greenland and Antarctica is directly dependent upon the buttressing by ice shelves, and that those ice shelves are in some places undergoing destabilization because they are in contact with anomalously warm oceanic waters.

Considering, arbitrarily, the Southern Ocean around the Antarctic, and supposing also arbitrarily, that the nearsurface Southern Ocean at the coast is known from observations to be warming, one has now several puzzles: is the warming the result of a long-term trend, perhaps one dating back $100+$ years? Or is it of recent vintage (decades)? Is it caused by local meteorological shifts, or meteorological shifts that occurred decades or longer ago, remote from this region? Is the warming due to a change in the monsoon structure in the Indian Ocean over the last decade? The last century? Are changes still occurring in the Indian Ocean that suggest near-Antarctic warming will continue? Or is injection of compensating cold water from the Atlantic beginning? For long-term consideration, is any part of the ocean irrelevant? Depending upon the answers to these and other questions, the predictability of the system will be entirely different. Observing system design must confront these questions.

\subsection{Disparate Nature of Observations.}

We have no prospect of a single universal observation system. Satellites (with the arguable exception of GRACE (Gravity Recovery and Climate Experiment)) observe only surface properties. Floats, drifters, etc. are likely always to be sparse relative to the temporal and 
spatial variability being observed. Some measurements are compelling because they are comparatively cheap and easy (Argo, some boundary current transports, etc.); some are compelling because they provide otherwise unobtainable spatial structures (satellites); and some will be made simply because of the existing capability coupled with opportunism (the Bermuda and Hawaii time series, Orion-type observatories, XBTs). As the white papers show, all of these measurement types can be used; numbers of observations remain sufficiently sparse that none is demonstrably redundant. However, as technologies change, as experts retire or otherwise disappear, the community needs to develop much clearer notions of which data are most useful, which are too difficult to sustain, and what the cost-benefit ratios are in a complex range of trade-off problems. Historically, oceanic observations were the amalgam of the uncoordinated efforts of individual principal investigators or small groups, spread around the world; that observational construct is inadequate for climate change. Figure 2 depicts the data sets used in the Estimating the Circulation and Climate of the Ocean/Global Ocean Data Assimilation Experiment (ECCO-GODAE) calculations of the Heimbach et al. (2010). (3).

\begin{tabular}{|c|c|c|c|c|c|}
\hline DATA TYPE & Source & Spatial Extent & Variable(s) & Duration & $\begin{array}{l}\text { Number of } \\
\text { values }\end{array}$ \\
\hline Altimetry: TOPEX/POSEIDON & PODAAC & $\begin{array}{l}\text { Global, equatorward of } \\
65 \text { degrees }\end{array}$ & $\begin{array}{l}\text { height anomaly, } \\
\text { temporal average }\end{array}$ & $1993-2005$ & $4500 /$ day \\
\hline Altimetry: Jason & PODAAC & $\begin{array}{l}\text { Global equatorward of } \\
65 \text { degrees }\end{array}$ & $\begin{array}{l}\text { height anomaly, } \\
\text { temporal average }\end{array}$ & $2002-2005$ & $4500 /$ day \\
\hline Altimetry: Geosat-followon & US Navy, NOAA & $\begin{array}{l}\text { Global, equatorward of } \\
65 \text { degrees }\end{array}$ & height anomaly & $2001-2005$ & $\begin{array}{l}4300 / \text { day } \\
\text { (gridded) }\end{array}$ \\
\hline Altimetry: ERS-1/2, ENVISAT & AVISO & 81.5 degrees & height anomaly & $1995-2005$ & $3800 /$ day \\
\hline Hydrograp hic olimatology & Gouretski and Koltermann (2004) & $\begin{array}{l}\text { global, 30om to } \\
\text { seafloor }\end{array}$ & temperature, salinity & $\begin{array}{c}1950-2002 \\
\text { inhomogeneous } \\
\text { average }\end{array}$ & 16 million \\
\hline Hydrograp hic climatology & $\begin{array}{c}\text { World Ocean Atlas (2001). Conkright et } \\
\text { al. (2002) }\end{array}$ & $\begin{array}{l}\text { global to } 300 \mathrm{~m} \\
\text { global, all seasons, to }\end{array}$ & temperature, salinity & $\begin{array}{l}\text { average seasonal } \\
\text { cycle }\end{array}$ & included above \\
\hline CTD synoptic section data & Various, including WOCE Hydro. Prog. & $\begin{array}{l}\text { global, all seasons, to } \\
3000 \mathrm{~m} \text {. } \\
\text { global, but little So. }\end{array}$ & temperature, salinity & NA & 17 thousand \\
\hline XBTs & D. Behringer (NCEP) & Ocean & temperature & $1992-2005$ & 1.4 million \\
\hline ARGO Float profiles & IFREMER & global, above $2500 \mathrm{~m}$ & temperature, salinity & $1997-2005$ & 2.1 million \\
\hline Sea Surface Tomperature & Reynolds and Smith (1999) & global & temperature & 1992-2005 & 5.3 million \\
\hline Sea Surface Salinity & $\begin{array}{l}\text { Etudes Climatiques de l'Oce'an Pacifique } \\
\text { (ECOP) }\end{array}$ & tropical Pacific & salinity & 1992-1999 & 24,238 \\
\hline TMI & NASANOAA & global & temperature & $1998-2003$ & 1.5 million \\
\hline Elephant Seal Profiles & SEaOS, U. St. Andrews & $\begin{array}{l}\text { So. Ocean, eastern } \\
\text { Pacific }\end{array}$ & temperature, salinity & 2005 & 21,000 profiles \\
\hline Geoid (GRACE mission) & $\begin{array}{c}\text { GRACE Project. (GGMO2C_DOT_cel6. } \\
\text { Tapley et al. (2003) }\end{array}$ & global & $\begin{array}{c}\text { mean dynamic } \\
\text { topography }\end{array}$ & NA & 1 degree resol. \\
\hline Bottom Topography & Smith\&Sandwell(1997)+ETOPO5 & $\begin{array}{c}\text { Smith/Sandwell to } \\
72.006, \text { ETOPO5 to } \\
79.5\end{array}$ & water depth & NA & 1 degree resol. \\
\hline FORCING: & & & & & \\
\hline Windstress-scatterometer & NCEP/NCAR reanalysis Kalnay et al. & global & stress & $\begin{array}{l}1992-99,7 / 1999- \\
2005\end{array}$ & $\begin{array}{l}9.4 \text { million } \\
\text { 192x94 Gaussian } \\
\text { grid (approx. } \\
1.875 \text { deg) } 6\end{array}$ \\
\hline Windstress & 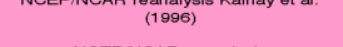 & global & $\begin{array}{c}\text { stress } \\
\text { sensible +latent }\end{array}$ & 1992-2005 & $\begin{array}{l}1.87 \text { deg) } 6- \\
\text { hourly }\end{array}$ \\
\hline Heat Flux & NCEP/NCAR reanalysis & global & heat & 1992-2005 & " \\
\hline Freshwater Flux & NCEP/NCAR reanalysis & global & evap-precip & $1992-2005$ & " \\
\hline $\begin{array}{c}\text { Short/long Wave Radiation } \\
\text { (experimental) }\end{array}$ & NCEPINCAR reanalysis & global & & $1992-2005$ & " \\
\hline $\begin{array}{l}\text { WITHHELD (as of April 2006): } \\
\text { tide gauges }\end{array}$ & & global, sparse & sealevel & & \\
\hline TOGA-TAO array & & equatorial oceans & velocity/temperature & & \\
\hline Tomographic integrals & & N. Pacific & heat content & & \\
\hline Florida Current transport & & Florida Straits & mass flux & & \\
\hline Float and Drifter Velocities & & Global & velocity & & \\
\hline
\end{tabular}

Figure 2. The data sets used at one time in the ECCO-GODAE estimates discussed in Heimbach et al. (2010).

\subsection{Need to consider all data.}

Because few data appear to be redundant, and because they generally measure disparate aspects of the ocean, the arbitrary suppression of a major data type in any discussion of the system (a) throws away potentially important information and, (b) raises doubts about whether some explanatory story of the retained data is not actually inconsistent with the undiscussed observations. For example, discussions of inferred heat content changes over large areas, as determined from in situ data that do not discuss the corresponding altimetric signatures, are omitting a very important piece of information. The history of science carries the 
lesson that inconsistencies among observations are the way in which new insights most often appear.

\subsection{Need for Synthesis with Theory.}

Much of what is known about the ocean, and climate more generally, rests with the equations of motion and thermodynamics. The complexity of the Navier-Stokes and related equations is such that their most flexible use has to be in numerical form. To exploit the disparate data sets (quantitatively combining a Kuroshio transport estimate, with an SST change in the eastern tropical Pacific 10 years before, with knowledge of Aleutian sea ice coverage through time can only be done through the use of a numerical model). Nonetheless, understanding of data requires picking-apart the otherwise extremely complex interactions that these equations embody, and thus a truly useful synthesis also requires using simpler theories. An oceanic model responding to shifts in wind stress, and constrained also by the wide variety of oceanographic data might suggest that some region is in Sverdrup balance. However, if the corresponding western boundary current in the model does not respond, as Sverdrup balance requires, one is led to try to understand the presumably more complicated physics that must be operating. The range of models that have to be used is very wide: from full, global eddy-resolving ones, to purely linear analytical theories. None is redundant, all are necessary, and all must be used cautiously when applied to the real ocean.

\section{5 - 3.6 Formal Estimation}

Another lesson of history is that as sciences mature, they necessarily become more quantitative. Estimation procedures, including meteorological data assimilation, are almost universally forms of least-squares, and in least-squares, solutions depend directly, and sometimes dramatically, on the errors assigned to data and to models. Furthermore, solutions are much less useful when unaccompanied by estimates of often-complex error or uncertainty structures. When predictions are made of societally important elements of climate (droughts, sea level rise), and whose skill may not be known for decades, estimates of uncertainty are crucial (in contrast with weather forecasting, where only hours or days are required to determine forecast skill).

\subsection{Forecasting}

In a forecast system, the major emphasis has to be on constructing an initial state that is optimized for the best forecast. That goal is distinctly different from one that tries to optimize knowledge of the state over a finite, past, interval (in some circumstances, optimization over the past interval is part of the algorithm for initial condition construction, but such methods are not universally used). So in particular, in weather forecasting, the tendency of the system to jump when data are included at analysis times, or the lack of global scale balances of energy, fresh water, and enthalpy have little or no impact on a weather forecast over hours and days. The so-called atmospheric reanalyses, which are constructed using weather forecast models and analysis systems, are almost impossible to use for climate purposes, as they do not satisfy global budget requirements (and have such difficult-to-deal with features as implied heat transport by the continents; see Trenberth and Solomon, 1994). Ultimately, we require coupled state estimation systems, exploiting both atmospheric and oceanic observations and dynamics.

3.8 $\mathrm{We}$ are seeing the publication of putative predictions of future climate states, in some cases involving major societal impacts (sea level rise, droughts, etc.). These are rarely if ever accompanied by useful statements of their reliability. An analogy might be the prediction of a major earthquake in Rome, to occur in the next 5 years with magnitude 7 . Societal response would be quite different if the prediction is believed to have a $95 \%$ skill (5\% probability of its not occurring), as opposed to a $5 \%$ skill (95\% probability of its not occurring). Surely, the climate problem requires similar statements of confidence.

That some elements of climate are predictable is hardly in doubt: the seasonal cycle of temperature, the mean temperature of the ocean, etc. are all predictable with great accuracy decades into the future, at least. As one goes further into the future, even these robust properties will lose some predictive skill. Other elements of the climate system have a poorly understood predictability: e.g., can one usefully predict ENSO (El Niño/Southern Oscillation) more than 6 months in advance? Is the mid-latitude Pacific sea surface temperature predictable with useful accuracy 20 years in advance? For the most part, these questions can be answered only with properly initialized system states, and only the state estimation systems are capable of combining data and models in such a way as to address the possibility of prediction. (Predictability studies with assumed perfect initial conditions can produce grossly unrealistic results.)

\subsection{Long Duration Issues}

As the geography of ocean variability has been gradually filled, the new observational frontier has become duration. The need for very long records, much longer than we now have, is plain. 


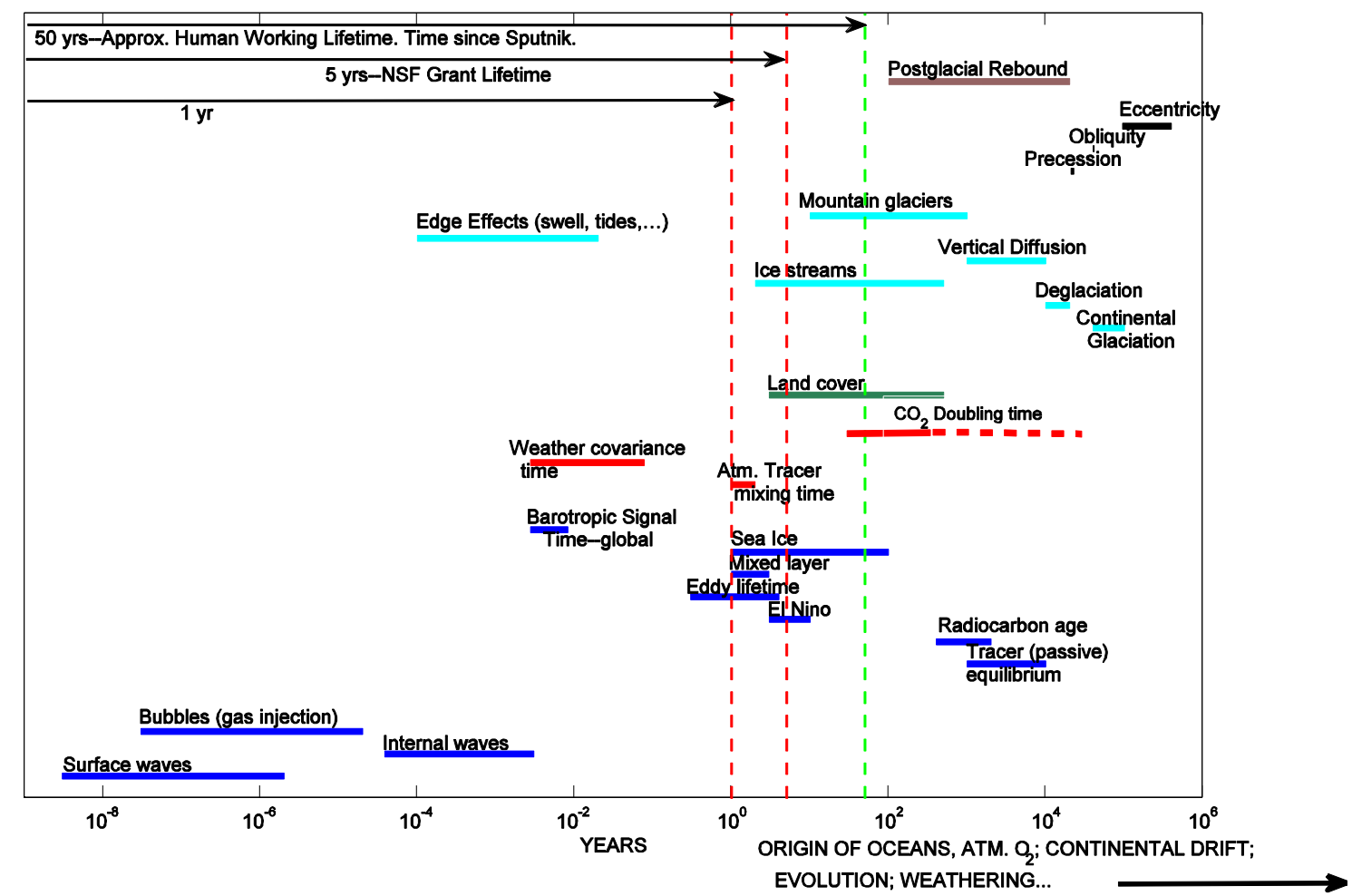

Figure 3 A subset of the time scales involved in understanding climate. They range from seconds to the age of the Earth. Many of them are beyond the one, five or even 50-year time spans of funded projects or human working lifetimes. The existence of such long times within the climate system has to play a prominent role in the design of any observational

system intended to understand the behaviour of the climate system. A rough color coding is used for phenomena predominantly ocean, land, etc. CO2 doubling time is partly dashed as the modern value is so much shorter than the historical ones and subject to change

Figure 3 shows an estimate of some of the time scales embedded in the climate system---many of them are far longer than any existing instrumental record. It is often argued that there is no way to generate long time series without short-term goals, and meteorological data are often used as the example of how to do it. Unfortunately, the metaphor is very misleading. It is extremely difficult to find any meteorological data set pieced together over long periods that does not raise as many questions as it answers (Thompson et al., 2008; Elliott and Gaffen, 1991; Wöppelmann et al., 2006): technologies change; calibrations lapse; gaps appear; sampling distributions change greatly. The problem is not physically impossible---but it is difficult to sustain scientific oversight and interest while long enough records accumulate. Figure 4 is one example of the issues, taken from Elliott and Gaffen (1991). Baker et al. (2007), Wunsch et al. (2009, unpublished) discuss this issue explicitly.

\section{NETWORK DESIGN AND UNCERTAINTY}

Taking the point of view that we are discussing an observing system that would be put in place over several years, and that it would run (with future modifications, probably major ones as technology and understanding advance) indefinitely, we should consider the investment of time and money required to fully understand what we are doing, and we should attempt as far as possible to get it right. Part of the burden of "getting it right" comes from the recognition that a failure now will greatly limit the understanding of oceanic climate change by future generations dependent upon the long records established now.

Although there is a considerable literature on what is often called experiment design, it is rarely done properly, and to my knowledge, has never been applied to open-ended, global scale, climate problems. Such studies are not easy, requiring both a detailed understanding of the physics (or chemistry or biology), of the workings of specific observational techniques as they already exist, and could exist with time and investment, and tradeoffs of cost and ease of use. They are also largely unrewarding to the scientific community because they only discuss hypothetical scientific issues, rather than drawing immediate science conclusions. It is thus perhaps unsurprising that examples of useful 
studies are not commonplace. However, if one is going to spend billions of euros and deal with climate change problems with societal consequences of trillions of euros, the need is compelling.

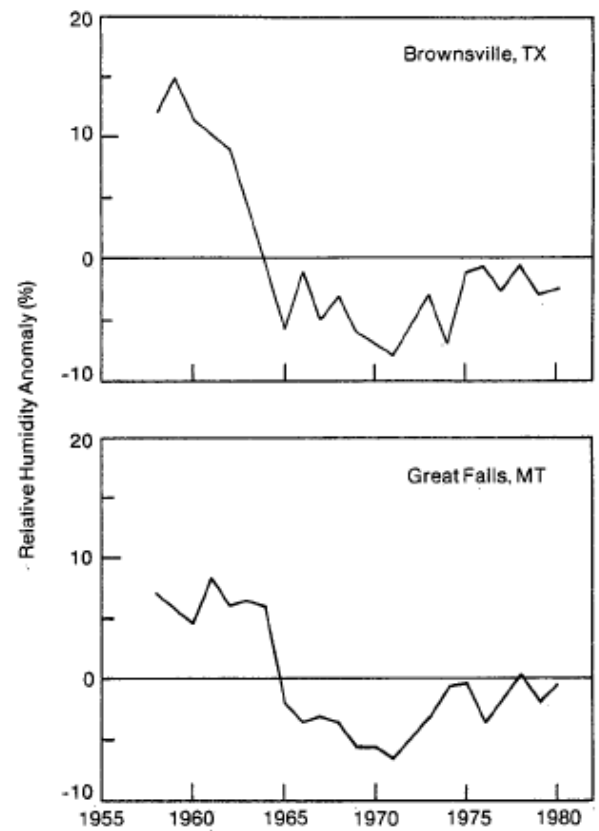

Figure 4 Relative humidity at $500 \mathrm{mb}$ (from Elliott and Gaffen, 1991) showing an apparent step or trend arising from the practice of reporting values of less than $20 \%$ as missing. An example of the kind of posterior issues that greatly complicate time series obtained for short term purposes but used to study climate.

The existing state estimation/data assimilation systems provide, in principle a number of approaches to answering questions about (1) what should be measured and, (2) how effective would be the results? The word "systems" is emphasized because as already alluded to, the general circulation models that are the focus of much of the attention are only one piece of the required analysis, which needs deep insight into measurement capabilities, costs, ease of use, sustained calibration, and the possibilities for improvement. The theory of all this is straightforward:

(A) Define an objective (e.g., minimizing the uncertainty in carbon uptake, or bottom water formation rates, or meridional heat transports). Call this objective function $J$.

(B) Choose a model believed to capture the underlying physics/chemistry/... along with a quantitative statement of its errors

(C) Define the set of observations to be considered (drifters, altimeters, tide gauges, tomography, floats, etc.) along with the errors in the system (drifter displacements accurate to $0.1 \mathrm{~km}$, altimeters with known frequency/wavenumber spectrum of uncertainty, etc.) and any known physical limitations or requirements (maximum of 10,000 drifters; no more than 3 altimeter satellites; at least one scatterometer, etc.) and the associated costs of each element.

(D) Write a code driving the model to consistency with any possible mix of observations, with consistency properly normalized by the sum of the particular model and data errors.

(E) Write a modified objective function, $J^{*}$, which weights $J$ relative to other optimization requirements (e.g., to also minimize costs, or minimize the manpower required to sustain the system, or to distribute the costs over as many countries as possible, etc.).

(F) Analyze the uncertainty of the result to understand its robustness.

(G) Build the optimized system.

As in many practical problems, it is easy to write the theoretical requirements, but exceedingly difficult to carry out the recipe.

Of all the elements listed above:

(A) Is the most important and difficult. Climate change involves a huge variety of elements (temperature, precipitation change, extreme wind events, sea ice cover and ice sheet volumes) on an equally extreme variety of space and time scales. (What is more important? The annual average global mean SST, or its values under the Aleutian low during January?). Can there be some agreement on an ordered (priority) list of the goals? Methods do exist for multiple goal optimization.

(B) Probably more attention has been paid in the past to model capability than any other element of the list. Models differ in their skills and cannot be regarded as all equivalent. Unfortunately, little is known of the formal structure of model errors as functions of region and times of integration. One model may be excellent for tropical physics over two or three years, but extremely poor in computing carbon uptake at high latitudes over a decade. If model errors were known even approximately, much of the difficulty in employing different models would vanish.

(C) Hypothetically there is no limit on the number of observational techniques that can be considered, as long as they can be related to what any particular model is capable of computing (if observations of the large-scale magnetic field variability induced by the ocean were to be used, a model would need to be constructed to calculate that. We know how to do it.) The most difficult problems lie with formulating the errors (usually issues of spatial and temporal covariances rather than standard errors of a particular sensor), and with insight into ease of use and calibration, and potential improvements, written quantitatively. 
(D) Calculating data estimates from a model state is generally well understood, and is done in all of the existing systems.

(E) Another strong matter of judgment---how should one weight costs against e.g., the ability to determine ocean heat uptake to an accuracy of $3 \mathrm{~W} / \mathrm{m}^{2}$. What are the other considerations?

(F) There are known methods for evaluating uncertainties ranging from brute force Monte Carlo (ensembles) to calculations of inverse Hessians. One can distinguish perturbation uncertainties from finite amplitude ones. The story here is primarily one of computational cost---we are generally unable to implement these methods on existing systems. But, if it were deemed important enough, it is clear that it could be done.

\section{WHAT'S BEEN DONE SO FAR}

As outlined, a rigorous analysis of the efficacy and costs of observing systems is a major undertaking that is unlikely to be carried out any time soon, and certainly not before decisions must be made about what we do in the next several years. It is thus useful to examine existing knowledge and working techniques.

For more or less homogeneous observing techniques whose spatial coverage varies greatly with time, the major issue becomes the change in accuracy of specific objectives that the systems already compute. Thus as the Argo float deployments shifted from primarily regional to global, the accuracy with which the estimate e.g., of oceanic heat content could be made, clearly changed.

At least two approaches are comparatively easy to employ. The first fixes the oceanic state e.g., over a year, calculates the model heat content, and then recalculates the now-known heat content using two or more different float coverages. This result does provide insight. It does not, however, take advantage of the model skill at dynamically and kinematically interpolating the data. Thus using any one of the known finite time interval estimation methods, one can constrain the model with float data (having deliberately, but realistically first producing an erroneous model state), and compute the heat content using the two different coverages. At issue, here is the realism of the data errors, but there is no fundamental difficulty. Formal total system error estimates can be done today using simple ensemble methods, although there are issues of computer resources, and whether the ensembles are realistic depictions of the population of possible solutions (how are the ensembles created?).

In similar fashion, one can compete various observing methods against each other. Carry out the above experiment by first using floats, then using altimeter data, and then using both and evaluate the results.
As with all these methods, the inferences will depend upon the objective. Whether they are sensitive to the model choice can of course be addressed by using more than one model. They are cut-and-try methods, not permitting one to answer the question of whether there would have been a more efficient geographical deployment, except to postulate it, and compare the results. No optimum is available. One example of such a calculation, from Oke et al. (2010) is shown in Fig. 5.

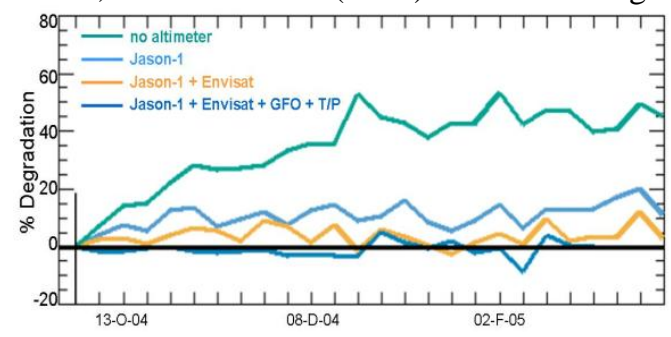

Figure 5 Dependence of model forecast skill on number of altimeters---here assumed to correspond to those that have actually existed, but not to some hypothetical optimal constellation (Oke et al., 2010).

Formal optimization methods are also known (e.g., Barth, 1992) and have been used in demonstration projects. They are expensive in computer time, but as with most such techniques, if the goal is sufficiently important, it is unlikely that limited computer power would prevent their use.

\section{ADJOINT SENSITIVITIES}

As discussed in numerous publications (e.g., Losch and Heimbach, 2007; Dutkiewicz et al., 2006), the theory of adjoint operators provides quantitative information on the sensitivities of GCMs (Global Circulation Models) (or any other) model or model output (heat content, carbon uptake, vorticity generation rate ...), to almost any modifiable element within the model---ranging from bottom topography to mixing coefficients to meteorological forcing. These sensitivities, formally the solution to the adjoint or dual model, contain all the structures of the forward model, and thus one has the same problem encountered in discussing conventional forward modelling---the full three-dimensional, timevarying elements of the ocean circulation produce an overwhelming set of quantitative measures of the controls in oceanic variability. Depicting and understanding such fields is not so simple.

Figure 1 above and Fig. 6, taken from Marotzke et al. (1999), depict the sensitivities (partial derivatives) of the oceanic heat transport to a variety of perturbations. In the latter, normalization by the estimated uncertainty of the field is used to remove the sensitivity to parameters which might be known essentially perfectly. 


\section{MORE GENERIC ISSUES}

As noted in the introductory comments, I have focussed on long time scales and the physical problems. However, many, if not most, of the problems apply to biogeochemical or ecosystem sampling, and with some clear simplifications, to short-range problems.

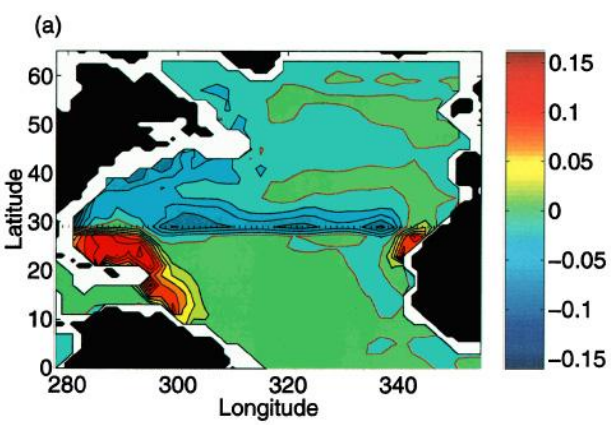

Figure 6 From Marotzke et al. (1999) showing the sensitivity of the 1993 annual mean heat transport across $29^{\circ} \mathrm{N}$ to sea surface temperatures on 1 January 1993. Calculation is from the adjoint sensitivity of an early ECCO model.

The ultimate global nature of perturbations contributing to the disturbance of any one point does show that socalled choke-point strategies---making measurements e.g., in the Drake Passage or Florida Current---while appealing and economical can only document the existence of change. They cannot provide information about causes and thus they ultimately fail as climate observing systems.

\subsection{Short Time/Space Scale Problems}

To the degree that the goal is short-term analysis and/or forecasting, several advantages are immediately obvious, as the analogy of weather forecasting shows: (1) Knowledge of system skill accrues sufficiently rapidly that one can continuously modify the system to experiment with improvements. Although most ocean forecasting has time scales longer than the hours or days of the weather problem, knowledge of skill on weekly or monthly time scales is clearly advantageous in that forecast problem, as compared to that on decade or century time scales that many climate problems confront. (2) Forecast skill, as opposed to what can be called state estimation can ignore many practical issues. In the same way that weather forecasters do not concern themselves e.g., with balancing the global water or energy cycles, ocean mesoscale forecasters need not worry about global mass or heat balance. Similarly, weather forecast models typically jump at the analysis time, as the model is pushed toward observations, some times with efficient but crude methods (e.g., nudging). Such adjustments lead to improved forecasts but typically preclude analysis of heat or freshwater or momentum budgets. (4) Calibration issues typically arise only over long time scales, when observational systems can drift, or the technology changes. If such shifts and drifts occur over time or space scales long compared to the scales of interest, comparatively simple methods (trend removal for example) exist for making adequate corrections. For climate purposes, issues of slow degradation, or technology shifts can become the major problem (e.g., Thompson, et al., 2008).

\subsection{Biogeochemical and Ecosystem Problems}

The issues for more general areas are essentially identical to those in the physical problems: they require defining the goal(s), their relative importance, and the accuracies with which they must be met; some knowledge of the sampling requirements (how often in space and time, whether global coverage is required); understanding of the calibration requirements, etc. To the extent that models are available, that are believed to have sufficient realism to provide useful estimates from the data, they can be used to define sensitivities and uncertainties. Thus, the problem of temperature sensitivity of volume transports is mathematically identical to that of nutrient sensitivity of primary productivity estimates, albeit, the models may be in different states of maturity. Nonetheless, the exercise of calculating these sensitivities with whatever skill is available is a prelude to whatever can be expected down the road.

\section{DOING IT}

It is easy to write papers exhorting others to carry out major studies. That a serious experimental design study resembling what is described above has never, to my knowledge, been carried out, is an indicator of its difficulties, and worthy of some comment on their nature. The technical component of the necessary work is reasonably well understood, and no obvious major obstacles appear to exist. What then is the issue?

Useful, comprehensive experimental design studies require considerable scientific insight and experience, and a large investment of their time by knowledgeable people. The result is not a scientific result per se; rather it is a plan for obtaining a scientific result. Such outcomes are not conventionally publishable, and do little to promote scientific careers.

Furthermore, the generic problem of climate is its duration. The existence of the time scales depicted in Fig. 3 means that "climate change" is not a problem that will be solved in 5 or 10 years. Instead, it is a problem that will come to be understood as future generations obtain increasingly long records (one hopes) and gradually piece together the elements of a remarkably complex system. Few scientists have the 
luxury of devoting their careers to obtaining data sets whose scientific insights will primarily benefit only their descendants (the gist of the problem discussed by Baker et al. (2007) and Wunsch et al. (2009) alluded to above.)

What one needs is an agency, either government or privately endowed, insulated from year-to-year funding cycles, with a commitment to obtaining the multidecadal data sets that will be required.

Experience with the existing state estimation programs suggests that the experiment design problem can be solved with comparatively modest resources. A working group of order 10 people, with expertise in observations, the use of GCMs, and some knowledge of estimation theory could, over a few years, make large contributions to the understanding of existing and realizable capabilities. The issue is for the climate-concerned community is to make such efforts sufficiently rewarding to attract the necessary talents.

\section{CONCLUSIONS}

The understanding of climate is an inter-generational problem---the time scales involved in climate change greatly exceed human working time spans, lifetimes, and the duration of the longest instrumental records. It is a disservice to the science and to society to claim that five or 10 more years of data will lead to a breakthrough in understanding: it is not going to happen.

The major effort must be to create observational systems that can be sustained, in a practical way, for many decades so that future generations will have the data giving them the possibility of ultimately claiming understanding. The sustenance of such systems requires keeping in mind all of the strictures listed above---the purpose of it all, the (probably changing) requirements on accuracy, precision and sampling, all while the technologies and scientific insights evolve.

The immediate challenge is to formulate the observational goals, to make them quantitative (how long, with what coverage, with what accuracy and precision) and to build in the ability to evolve with improving knowledge and technologies. Numerical machinery exists to carry out optimization exercises of many different types, combined with or independent of numerical models. This machinery can be expensive to use, but the costs are infinitesimal compared to the probable expenses of unanticipated or undetected climate change. Someone needs to begin!

\section{ACKNOWLEDGEMENT}

Supported in part by the ECCO-GODAE (Estimating the Circulation and Climate of the Ocean/Global Ocean Data Assimilation Experiment) program of the National
Ocean Partnership Program (NOPP), NASA (National Aeronautics and Space Administration) and the US NSF (United States National Science Foundation).

\section{REFERENCES}

1. Baker, D. J., R. W. Schmitt, and C. Wunsch, 2007: Endowments and New Institutions for Long-Term Observations. Oceanography, 20, 10-14.

2. Barth, N. H., 1992: Choosing altimeter orbits as a problem in experiment design. Oceanologica Acta, 15, 459-470.

3. Cessi, P., K. Bryan, et al., 2004) : "Global seiching of thermocline waters betwee(Stammer 2008)n the Atlantic and the Indian-Pacific Ocean Basins." Geophysical Research Letters 31(4)

4. Dutkiewicz, S., M. J. Follows, P. Heimbach, and J. Marshall, 2006: Controls on ocean productivity and airsea carbon flux: An adjoint model sensitivity study. Geophysical Research Letters, 33.

5. Elliott, W. P. and D. J. Gaffen, 1991: On the utility of radiosonde humidity archives for climate studies. Bulletin of the American Meteorological Society, 72, 1507-1520.

6. Geirsdottir, A., G. H. Miller, N. J. Wattrus, H. Bjornsson, and K. Thors, 2008: Stabilization of glaciers terminating in closed water bodies: Evidence and broader implications. Geophysical Research Letters, 35.

7. Heimbach, P. \& Co-Authors (2010). "Observational Requirements for Global-Scale Ocean Climate Analysis: Lessons from Ocean State Estimation" in these proceedings (Vol. 2), doi:10.5270/OceanObs09.cwp.42.

8. Losch, M. and P. Heimbach, 2007: Adjoint sensitivity of an ocean general circulation model to bottom topography. Journal of Physical Oceanography, 37, 377-393.

9. Marotzke, J., R. Giering, K. Q. Zhang, D. Stammer, C. Hill, and T. Lee, 1999: Construction of the adjoint MIT ocean general circulation model and application to Atlantic heat transport sensitivity. Journal of Geophysical Research-Oceans, 104, 29529-29547.

10. Oke, P. \& Co-Authors (2010). "Observational Requirements of GODAE Systems" in these proceedings (Vol. 2), doi:10.5270/OceanObs09.cwp.67.

11. Stammer, D. \& Co-Authors (2010). "Ocean Information Provided Through Ensemble Ocean Syntheses" in these proceedings (Vol. 2), doi:10.5270/OceanObs09.cwp.85.

12. Stammer, D., 2008: "Response of the global ocean to Greenland and Antarctic ice melting." Journal of Geophysical Research-Oceans 113(C6).

13. Thompson, D. W. J., J. J. Kennedy, J. M. Wallace, and P. D. Jones, 2008: A large discontinuity in the midtwentieth century in observed global-mean surface temperature. Nature, 453, 646-U5.

14. Trenberth, K. E. and A. Solomon, 1994: The global heat- 
balance - heat transports in the atmosphere and ocean. Climate Dynamics, 10, 107-134.

15. Wöppelmann, G., N. Pouvreau, et al., 2006: Brest sea level record: a time series construction back to the early eighteenth century." Ocean Dynamics 56: 487-497.

16. Wunsch, C., R. A. Schmitt, D. J. Baker, 2009. Climate Change as an Intergenerational Problem. Unpublished document. 